\title{
Impacts of Discharged Low-Temperature Water on Water Table and Temperature in the Riparian Zone
}

\author{
Bei Zhu*(**)†, Shiyan Wang*(**), Chang Liu**, Wei Su**(***), Jiapeng Wu**, Cunwu Li**** and Jingshi Shang** \\ *State Key Laboratory of Simulation and Regulation of Water Cycle in River Basin, Beijing 100038, China \\ **China Institute of Water Resources and Hydropower Research, Beijing 100038, China \\ ***College of Science and Technology, Hebei Agricultural University, Huanghua 061100, China \\ ****Guangxi Institute of Water Resources and Hydropower Research, Nanning 530023, China \\ †Corresponding author: Bei Zhu; zhubei_hhu@163.com
}

Nat. Env. \& Poll. Tech.

Website: www.neptjournal.com

Received: 16-04-2021

Revised: 14-05-2021

Accepted: 07-06-2021

Key Words:

Lateral hyporheic exchange

Discharged low-temperature

water

Water fluctuations

Temperature distribution

\begin{abstract}
We observed the water level and temperature in the lower stretch of the Hsin-an river in China for different times to show the characteristics of the water table and temperature in the riparian zone under the influence of discharged low-temperature water. The water table in the riparian zone showed a typical daily cycle change with a fluctuation range of $239.42-275.99 \mathrm{~cm}$, according to the findings. With increasing distance from the river, the amplitudes of the water table fluctuation were reduced, and the phases were lagged. In the high-temperature period, riparian temperatures range from $20.4^{\circ} \mathrm{C}$ to $26.0^{\circ} \mathrm{C}$, whereas in the low-temperature phase, temperatures range from $12.9^{\circ} \mathrm{C}$ to $19.2^{\circ} \mathrm{C}$. The temperature distribution in the riparian zone was described in the vertical direction as "warmer on the surface and cooler at the bottom" during high-temperature periods and "cooler on the surface and warmer at the bottom" during low-temperature periods, with the temperature gradient gradually decreasing with depth. There was clear temperature zonation in the horizontal direction during the hightemperature phase but none during the low-temperature period. The study will serve as a benchmark for future hyporheic zone ecological impact assessments.
\end{abstract}

\section{INTRODUCTION}

The hyporheic zone is a band of permeable, saturated sediment surrounding a river where surface water and groundwater mix, and includes riverbeds (shallow hyporheic zone), riverbanks, saturated sediments under dry bars (parafluvial hyporheic zone), and riparian and floodplain areas (floodplain hyporheic zone) (Jones et al. 2000, Tonina \& Buffington 2007, Zhou et al. 2014). The material and energy transfer between the riparian zone and the river is driven by the lateral hyporheic exchange, which plays a key role in the regulation of river ecosystem health (Casas et al. 2015).

The power station's diversion port is located in the reservoir's low-temperature layer (Harleman 1982), where the temperature is lower than that of natural water for the majority of the year. Low-temperature water flows downstream, changing the distribution of flow field and temperature field in the riparian zone through the lateral hyporheic exchange (Boutt \& Fleming 2009), having a significant impact on aquatic organisms, benthic organisms, and microbial communities, as well as the river ecosystem (Greenwood et al. 2007). The average water temperature of the Luotong Port, downstream of the Hsin-an river reservoir, was $19^{\circ} \mathrm{C}$ before the reservoir was built, and decreased by $5.5^{\circ} \mathrm{C}$ after the reservoir was built (Weiwu 2001). Casado et al. (2013) studied the water temperature of the Sauce Grande river in Argentina and revealed that water temperatures immediately below the dam were notably reduced, and diurnal cycles were reduced and delayed in magnitude. Several scholars have studied the impact of discharged low-temperature water on temperature distribution in the hyporheic zone. Gerecht et al. (2011) carried out a study at Hornsby Bend in the lower Colorado river of Texas using hydraulic and thermal measurements to identify the hyporheic zone's depth and determine its variation, both spatially and temporally. Molina et al. (2011) analyzed the temperature time series of the river course and riverbank of the Tuer river and found that the fluctuating river water temperature decays exponentially along the lateral riverbank, and the rate of decay is related to the groundwater velocity, thermal diffusion coefficient, and frequency of the temperature time series. Vogt et al. (2012) applied distributed temperature sensing (DTS) along optical fibers wrapped around tubes to measure high-resolution vertical temperature profiles of the unsaturated zone and shallow riparian groundwater. They found that the observed riparian groundwater temperature distribution could not be described 
by uniform flow, but by horizontal groundwater flow velocities with varying depth. Hucks et al. (2009) found that the temperature in the near-bank is significantly associated with the river temperature with a certain lag, while it is steadily away from the bank.

The fluctuating stage has a significant effect on the interaction between river water and groundwater downstream of the dam (Hancock 2002, Nilsson \& Berggren 2000, Hamilton 2005). Hanrahan (2008) monitored and analyzed the water pressure and temperature in the riverbed downstream of the dam and showed that the operation of a dam power station can reverse the direction and intensity of vertical hyporheic exchange. Arntzen et al. (2006) monitored the water pressure, temperature, and hydrochemical index in the hyporheic zone of a regulated, large cobble bed river in Columbia and reported that the vertical hydraulic gradient, water temperature, and hydrochemical reaction in the riverbed all responded to the fluctuating river flow. Based on this study, Fritz \& Arntzen (2007) further estimated the relationship between vertical exchange rate and river stage. Kiel \& Cardenas (2014) calculated the extent and duration of lateral hyporheic exchange throughout the Mississippi River network using a physics-based numerical model that considered the distribution of groundwater baseflow, river discharge, alluvium permeability, and river morphology.

Some scholars have studied the effect of reservoir operation on vertical or lateral hyporheic exchange at different scales. However, the in-depth quantitative characterization of the dynamic processes of exchange intensity and direction in response to river stage fluctuations has been minimal. This study carried out a hyporheic exchange test in the riparian zone downstream of the Hsin-an River dam, monitored the water level and temperature of the river and riparian zone, characterized the dynamic processes of lateral hyporheic exchange intensity and direction in response to river stage fluctuations, ad assessed the dam operations on fluid exchange and temperature conditions in the riparian zone.

\section{MATERIALS AND METHODS}

The study area is located in the riparian zone $\left(29^{\circ} 24^{\prime} \mathrm{N}\right.$, $119^{\circ} 2^{\prime}$ E) of the Hsin-an river in Jiande City, Zhejiang Province, China, approximately $20 \mathrm{~km}$ downstream of the dam. The annual range of river temperature at the study site affected by dam operation is $13.5-17.5^{\circ} \mathrm{C}$, and the fluctuation range of the river water level is as high as $1 \mathrm{~m}$, with a daily cycle. It is typical low-temperature water discharged from a reservoir. Seven observation wells G1, G2, G3, G4, G5, G6, and G7 were arranged in the riparian zone (Fig. 1). $\mathrm{G} 1, \mathrm{G} 2, \mathrm{G} 3, \mathrm{G} 4$, and G5 were in a transect perpendicular to the river, being $3.00 \mathrm{~m}, 5.79 \mathrm{~m}, 8.46 \mathrm{~m}, 10.81 \mathrm{~m}, 13.59 \mathrm{~m}$ offshore, respectively. G5, G6, and G7 were parallel to the river. The observation wells were made of plastic blind pipes. Each pipe was $4 \mathrm{~m}$ long with an outer diameter of $100 \mathrm{~mm}$ and an inner diameter of $80 \mathrm{~mm}$ and covered with a layer of extremely permeable non-woven geotextile. HM21 input liquid level transmitters (measuring accuracy: $0.1 \mathrm{~cm}$ ) were

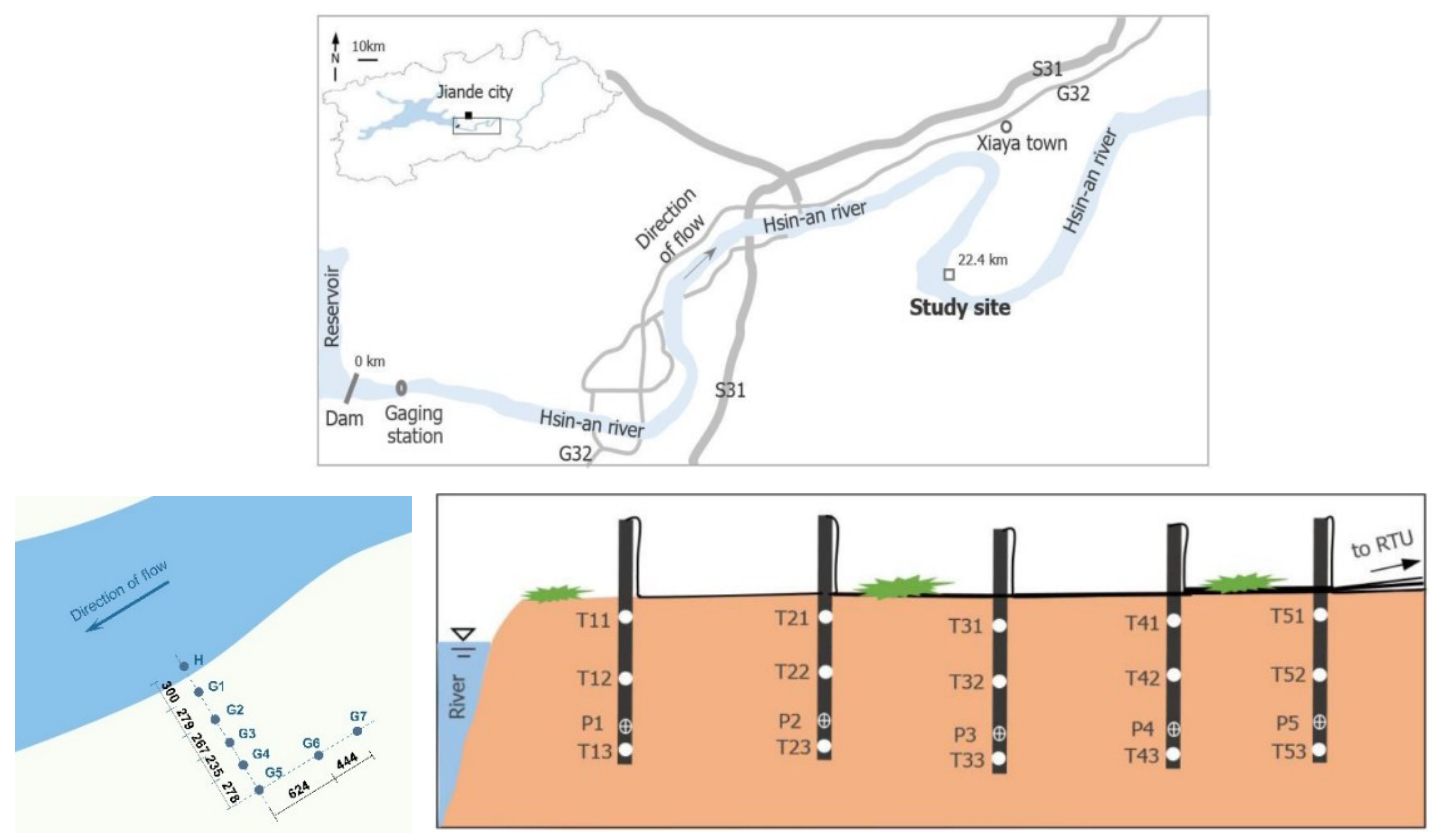

Fig. 1: Layout diagram of the study site and cross-sectional views of G1, G2, G3, G4, and G5 (T: a temperature sensor; P: pressure sensor). 
used for sensing pressure, and PT100 thermal resistance temperature sensors (measuring accuracy: $0.1^{\circ} \mathrm{C}$ ) were used for sensing temperature. To monitor the river's water level and temperature, a pressure sensor, and two temperature sensors were placed near the shoreline at $\mathrm{H}$. Temperature sensors were placed in the air and in the soil layer at the same time to monitor the air and ground temperatures. Using a temperature-water level analog signal automatic acquisition system, the temperature and pressure sensed by the sensors were automatically recorded and stored every $5 \mathrm{~min}$.

\section{RESULTS AND DISCUSSION}

The water table in the riparian zone simultaneously varied at different times of the day and different distances from the river. The interaction between the surface water and groundwater varied in different seasons. Overall, the water table fluctuated from $239.42 \sim 275.99 \mathrm{~cm}$ with an amplitude of $36.57 \mathrm{~cm}$ on September 4, 2014 (Fig. 2). At 22:00, the water table was the highest, the river stage was higher than the water table, and the river recharged the groundwater. At 14:00, the water table was the lowest, the river stage was lower than the water table, and the groundwater recharged the river. On December 3, 2014, the groundwater level fluctuated from $266.96-281.39 \mathrm{~cm}$ with an amplitude of $14.43 \mathrm{~cm}$. At 10:00, the water table was the highest, the river stage was lower than the water table, and the groundwater recharged the river. At 2:00, the water table was the lowest, the river stage was higher than the water table, and the river recharged the groundwater. The amplitude of the water table in Sep-
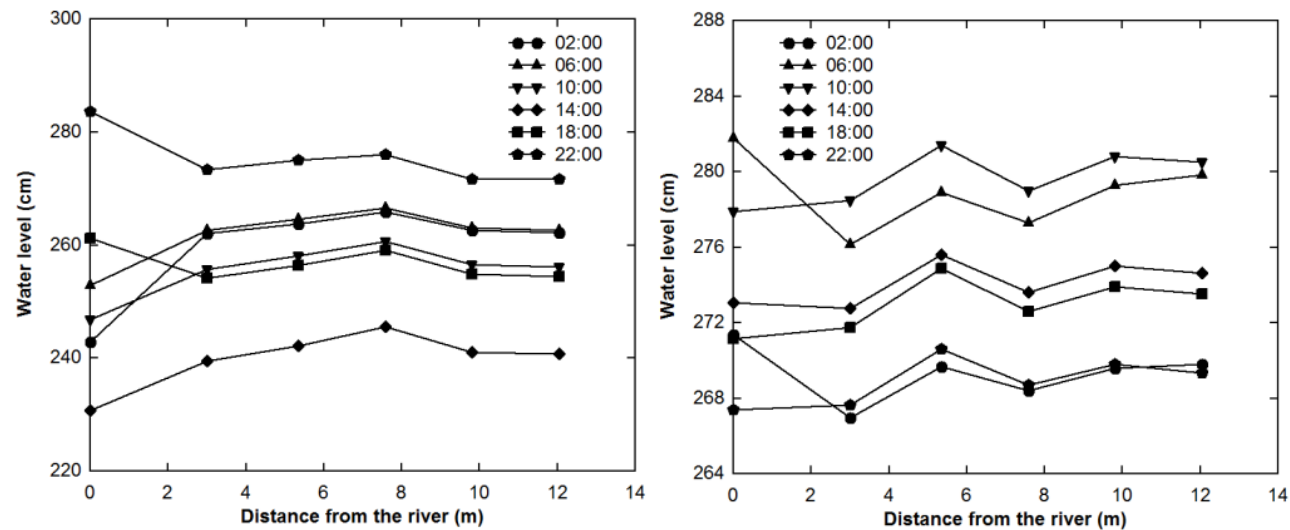

Fig. 2: Temporal and spatial distribution of the water table in the riparian zone (Left: September 4, 2014; Right: December 3, 2014).

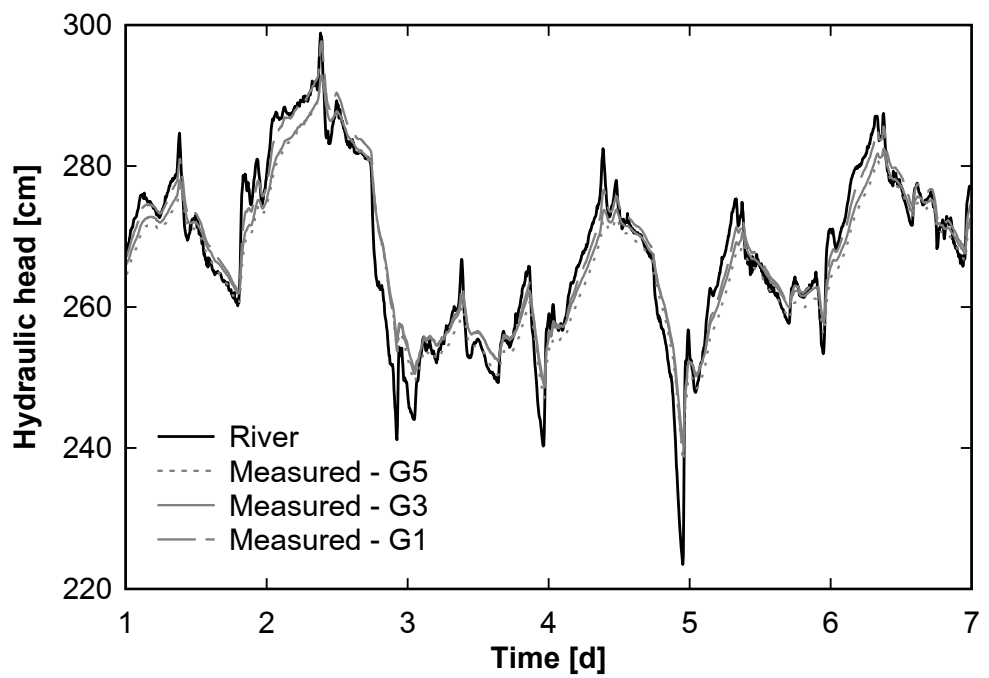

Fig. 3: Water table elevation time series at the study site river, G5, G3, and G1 denotes the water level of the river and each observation well, respectively. The lines G1, G3, and G5 are perpendicular to the river. The distances of wells G5, G3, and G1 from the river were 13.59, 8.46, and 3 m, respectively. Water table fluctuations were relatively attenuated and lagged relative to the river stage fluctuations. 


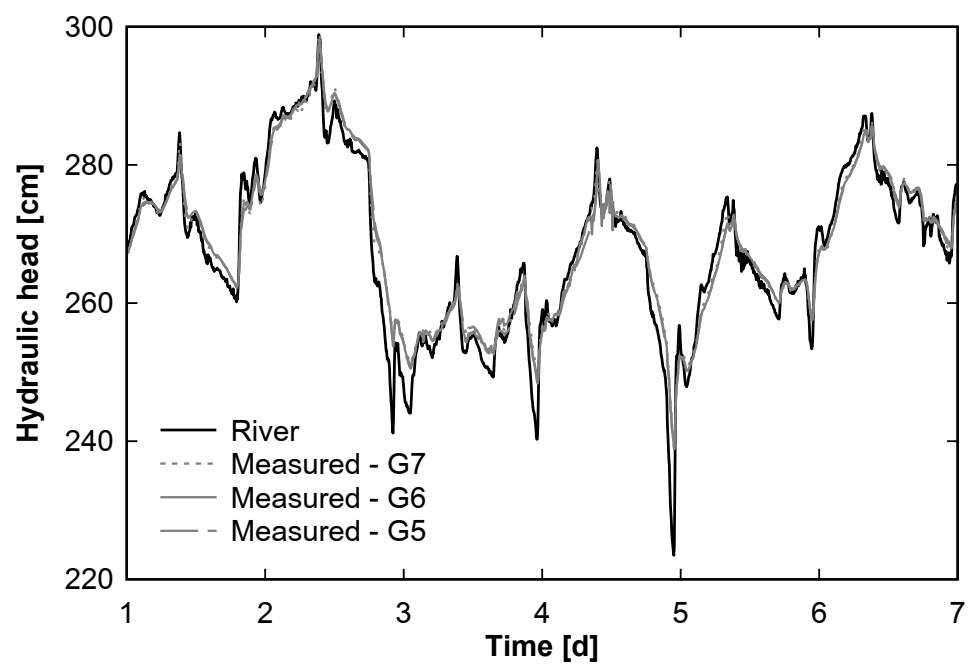

Fig. 4: Water table elevation time series at the study site river, G7, G6, and G5 denote the water level of the river and each observation well, respective1y. The lines of G7, G6, and G5 are parallel to the river. The water table fluctuations of G7, G6, and G5 were almost the same.

tember was higher than that in December, which indicated that the operation of the upstream reservoir was stronger in September than in December.

To study the response of the water table in the riparian zone to the fluctuating river stage, measured data of G1, G3, G5, G6, and G7 from November 28 December 3, 2014 were taken as an example for analysis. The lines G1, G3, and G5 are perpendicular to the river, and the lines G5, G6, and G7 are parallel to the river. During this period, the river stage fluctuated significantly, and the temperature remained in the range of $15.3-16.9^{\circ} \mathrm{C}$. The fluctuation of the river water level was approximately a sinusoidal curve, showing a typical diurnal variation (Fig. 3). The river stage fluctuated widely, ranging from $223 \sim 299 \mathrm{~cm}$. The highest value of the river stage appeared at 10:00 am and the lowest value at night. The response time and amplitude of different observation wells to the fluctuation of river stage were different, showing that water table fluctuations were damped and lagged away from the river. The amplitudes of the water table fluctuations of G1, G3, and G5 were $61 \%, 54 \%$, and $49 \%$ of the river stage, respectively, and the phase lags were approximately 6,11 , and 15 mins, respectively. G5, G6, and G7 were equidistant from the river, and the fluctuations of the water table in the three wells were almost the same, exhibiting amplitude

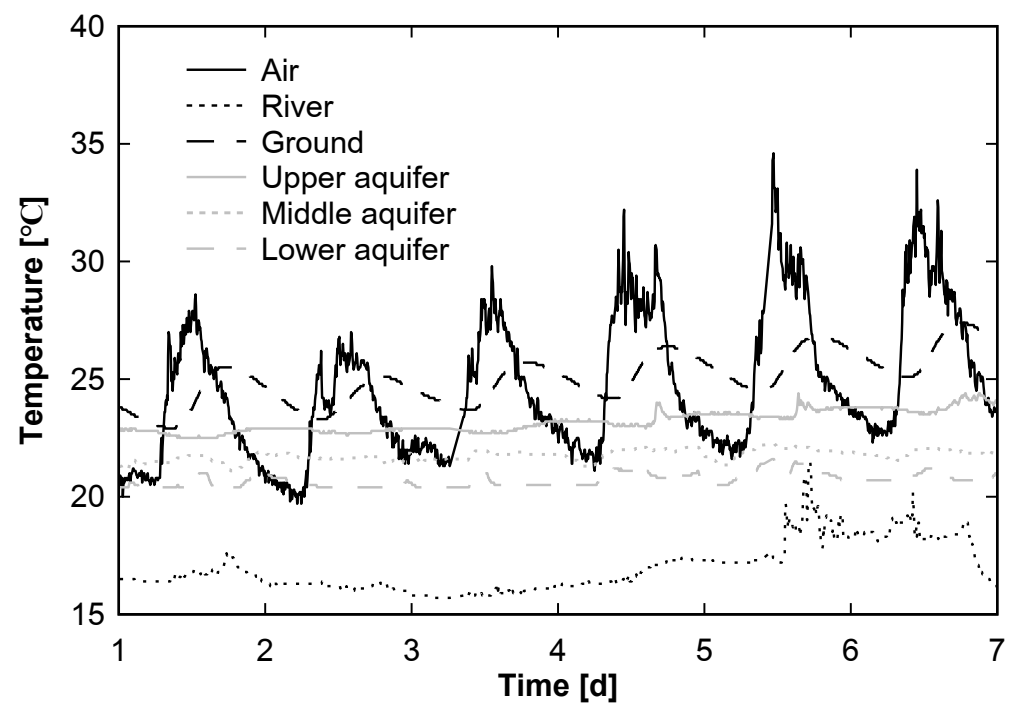

Fig. 5: Temperature distribution of air, river, ground, and groundwater in the riparian zone (high-temperature period). 


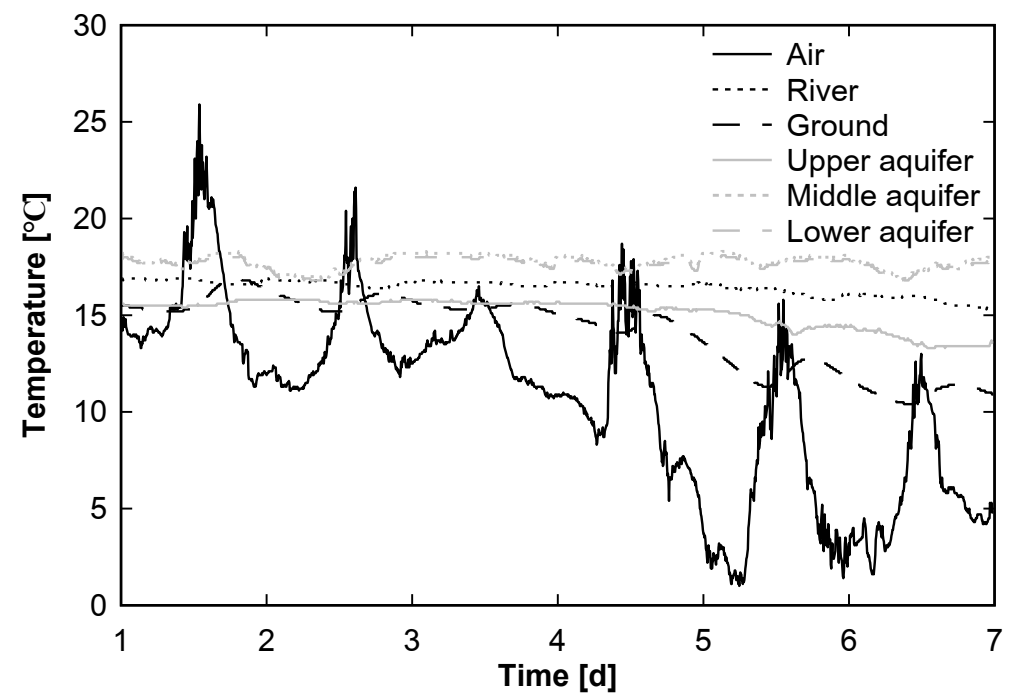

Fig. 6: Temperature distribution of air, river, ground, and groundwater in the riparian zone (low-temperature period).

attenuation when compared with the fluctuation of the river stage (Fig. 4). In other words, the riparian zone's fluctuating water table's amplitude attenuation was proportional to its distance from the river, and the oscillations in the water table were nearly identical at the same distance.

\section{Temperature Response}

During the monitoring period, the daily temperature showed a typical cyclic fluctuation (Fig. 5 and Fig. 6), with the highest, lowest, and average temperatures of $34.6,19.7$ and $24.7^{\circ} \mathrm{C}$ in the high-temperature period, and $25.9,1.0$ and $10.74^{\circ} \mathrm{C}$ in the low-temperature period, respectively. The ground temperature variation was similar to that of air temperature, but its amplitude was approximately one-third of the air temperature, and its phase lagged behind air temperature, indicating that a certain duration was necessary for the ground to be heated by the sun. The river water temperature was affected by the low-temperature water discharged from the upstream reservoir. The daily temperature fluctuation of the river was approximately $0.5^{\circ} \mathrm{C}$. The river temperature was about $16.97^{\circ} \mathrm{C}$ in the high-temperature period and $16.45^{\circ} \mathrm{C}$ in the low-temperature period. The highest and lowest temperatures were recorded in the evening and morning of each day, respectively, as is typical of the river's daily temperature range. The temperature change in the downstream river caused by the operation of the upstream reservoir was smaller than in the natural river.

The dam-induced low-temperature water discharged into the downstream river, and the interaction between the river and riparian aquifer caused a change in the heat transfer and exchange in the riparian zone, which led to a change in the temperature distribution in the riparian zone. Under the bidirectional radiation of the lower low-temperature water layer and the higher natural temperature surface layer, the infiltration of low-temperature water will result in a non-isothermal soil environment, resulting in the redistribution of the temperature field. To further clarify the temporal and spatial distribution of temperature in the riparian zone and the dynamic characteristics of diurnal cycle changes, contour maps of profiles in the riparian zone were drawn at different times of the day for the high-temperature and low-temperature periods (Fig. 7 and Fig. 8). The temperature contours of the sections G1, G2, G3, G4, G5, and the river sensor were plotted at a 4-hour interval from 2:00 22:00 on September 4, 2014, and December 3, 2014. The boundary between the river and bank was located at $\mathrm{x}=0$. The riparian surface was $\mathrm{y}=0$, and $\mathrm{y}<0$ was below the surface.

As shown in Fig.7 and Fig.8, the spatial distribution of temperature in the riparian aquifer was uneven and changed over time. During the monitoring period, the temperature of the riparian aquifer varied between $20.4 \sim 26.0^{\circ} \mathrm{C}$ in the high-temperature period and between $12.9-19.2^{\circ} \mathrm{C}$ in the low-temperature period. The aquifer of the riparian zone had obvious temperature stratification in the vertical direction, characterized as "warmer on the surface and cooler at the bottom" in the high-temperature period and "cooler on the surface and warmer at the bottom" in the low-temperature period. Moreover, the temperature gradient gradually decreased with depth. In the horizontal direction, it could be divided into low-temperature, medium-temperature, and high-temperature zones from near shore to far shore. The temperature zone area changes with time, showing that cold 

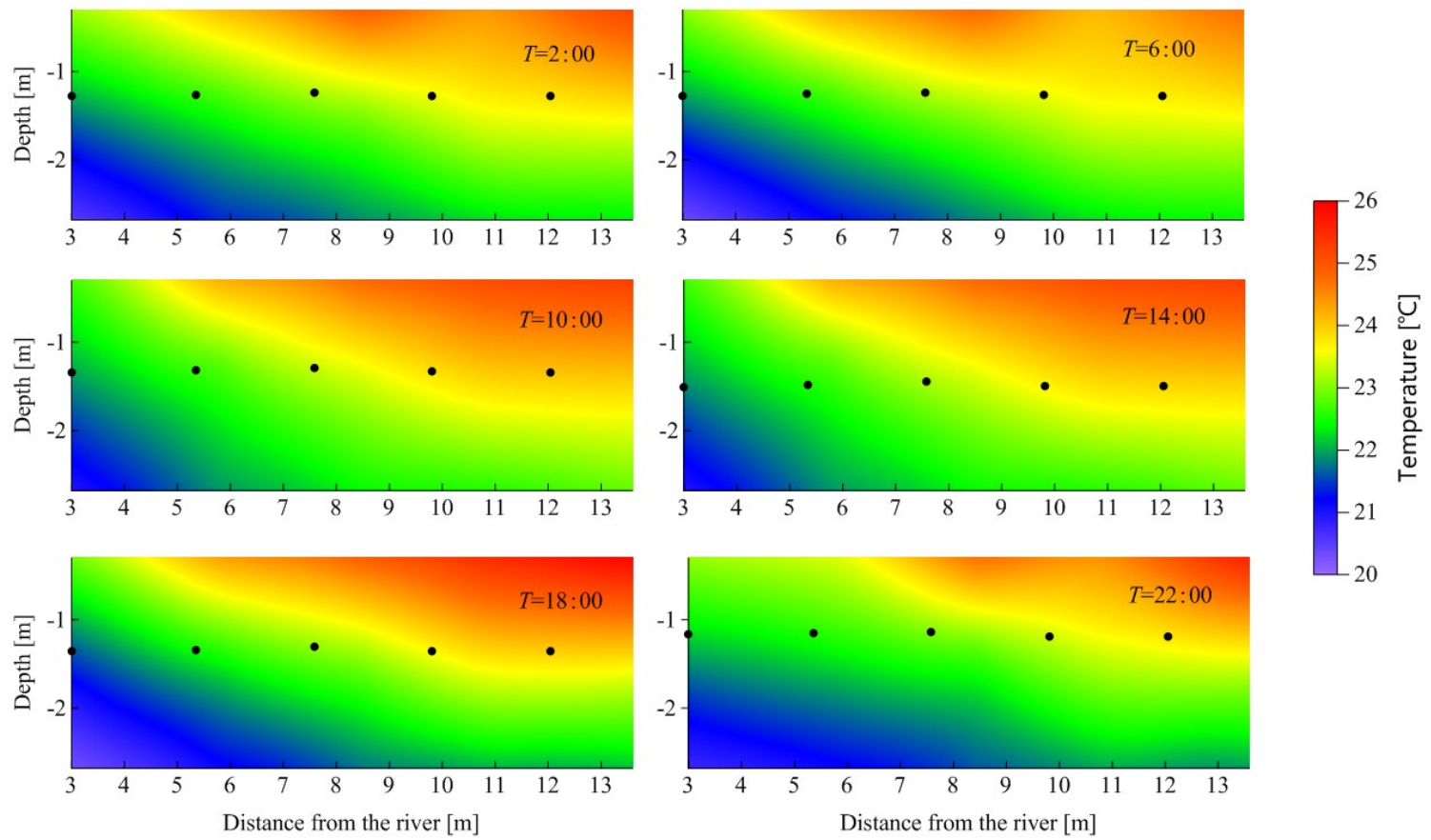

Fig. 7: Temperature distribution in the riparian zone at different times on September 4, 2014 (high-temperature period). The black spots represent the water levels in each of the monitoring wells
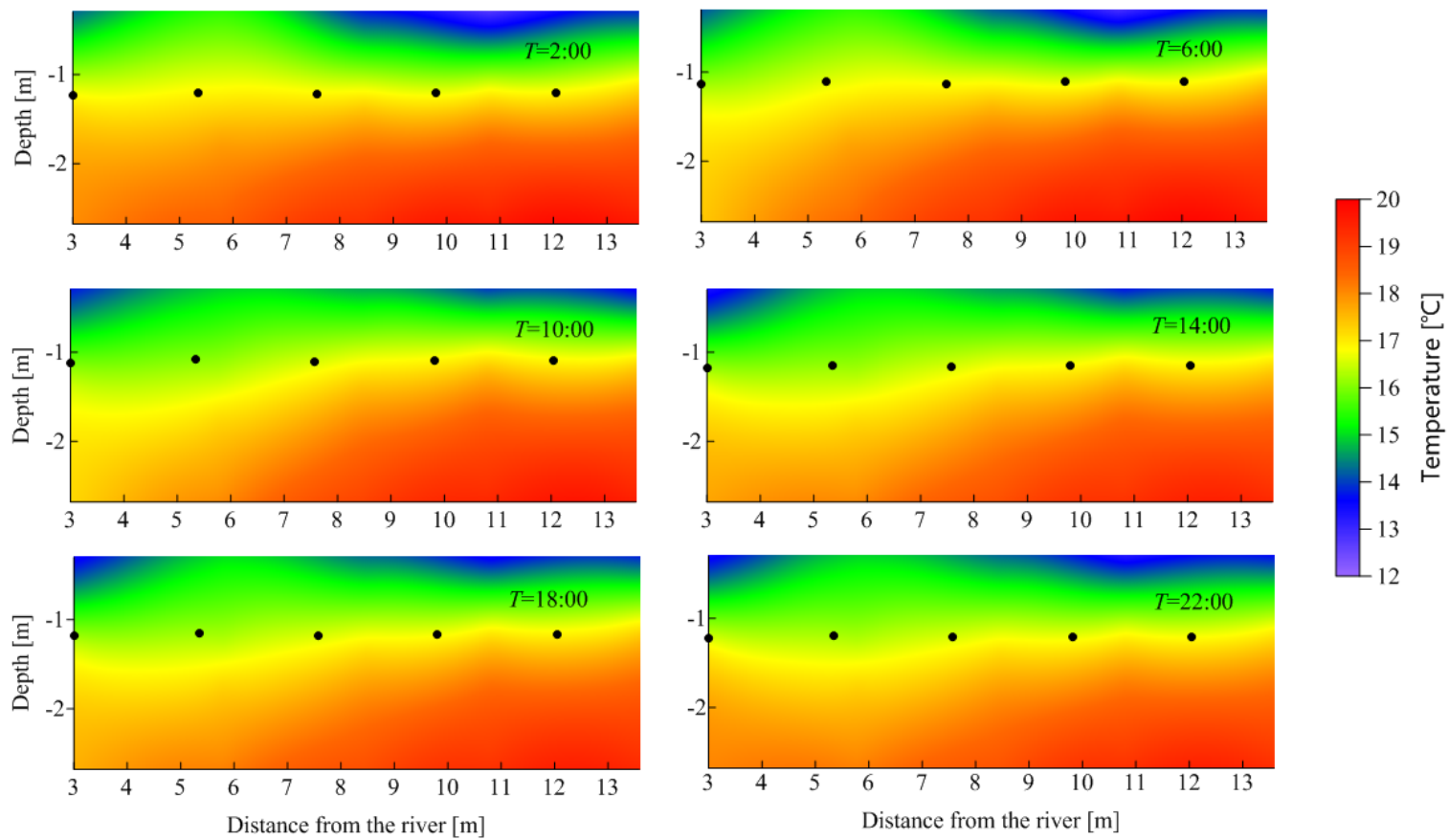

Fig. 8: Temperature distribution in the riparian zone at different times on December 3, 2014 (low-temperature period). The black spots represent the water levels in each of the monitoring wells. 
water diffuses at a distance and the temperature gradient gradually decreases in the high-temperature period, while there is no obvious zonation in the low-temperature period, and the temperature fluctuation amplitude in the high-temperature period is higher than that in the low-temperature period. This was because the magnitude and range of lateral hyporheic exchange in the riparian zone were much higher than those in the vertical direction, and the hyporheic exchange intensity was stronger in the high-temperature period, which promoted the lateral propagation and diffusion of temperature. Under the influence of solar radiation, the temperature in the shallow riparian aquifer obviously changed with time. Taking the high-temperature period as an example, the shallow layer temperature reached the maximum value at 14:00, and the area of the high-temperature region was the largest. When $\mathrm{T}=22: 00$, the area of the high-temperature region reached the minimum, and the area of the low-temperature region reached the maximum. This was because the temperature of the unsaturated soil and shallow aquifer increased with the increase in illumination intensity. With heat conduction, the temperature of the unsaturated soil and shallow aquifer increased and peaked at 14:00. The influence of air temperature on the temperature of the riparian zone got weaker as the illumination intensity reduced, the low-temperature zone began to expand, and the high-temperature zone gradually shrank.

\section{CONCLUSION}

This study investigated the dynamic processes of hyporheic exchange and temperature distribution in the riparian zone in response to dam-induced low-temperature water fluctuations downstream of the Hsin-an river dam by monitoring the temperature and water level of the river and riparian zone. The conclusions are as follows:

(1) The water table in the riparian aquifer showed a significant fluctuation between $223 \sim 298 \mathrm{~cm}$, a typical daily cycle variation. The fluctuations of the water table in the hyporheic zone were affected by fluctuations in the river stage: the farther it was from the river, the smaller the fluctuation amplitude was and the slower was its phase lag, that is, the slower was the response of lateral exchange intensity to river stage fluctuations.

(2) The temperature distribution in the riparian aquifer was affected by low-temperature water infiltration, which was shown as "upper warm and lower cool" in the high-temperature period and "upper cool and lower warm" in a low-temperature period in the vertical direction. Moreover, the temperature gradient decreased gradually with depth. The temperature distribution could also be divided into low-temperature, medium-tempera- ture, and high-temperature zones from near shore to far shore in the high-temperature period in the horizontal direction, and a gradually decreasing gradient was observed. However, there is no obvious division of temperature in the low-temperature period.

The hydrological variation in rivers caused by low-temperature water discharged from large reservoirs has a significant impact on the habitat structure and flow-temperature environment in the riparian zone. The mechanism of water exchange and temperature transfer in riparian zones can be used to quantitatively assess the effects of low-temperature discharged water on flow, temperature, and the ecological environment in riparian zones, as well as to improve overall river ecological health evaluation and coordination. The temperature in the riparian zone is affected by unsaturated layer temperature, river water temperature, and exchange rates between river and groundwater, while the temperature in the unsaturated layer is affected by light intensity and air temperature (Jie et al. 2014). The response mechanism of temperature in the hyporheic zone needs to be further studied quantitatively. Meanwhile, research on the response mechanism of the riparian hyporheic zone to biochemistry (such as redox reactions) and ecological changes (such as biocenosis) caused by dam operation at the basin scale still needs to be strengthened.

\section{ACKNOWLDGEMENT}

This research was funded by the Major Science and Technology Program for Water Pollution Control and Treatment (2018ZX07111003), National Natural Science Foundation of China(Grant No.91647212); IWHR Research \& Development Support Program (WE0163A052018, WE0163A042018, WE0145B422019, HTWE0202A242016), Program for Innovative Research Team of IWHR (WE0145B592017).

\section{REFERENCES}

Arntzen, E.V., Geist, D.R. and Dresel, P.E. 2006. Effects of fluctuating river flow on groundwater/surface water mixing in the hyporheic zone of a regulated, large cobble bed river. River Res. Appl., 22(8): 937-946.

Boutt, D.F. and Fleming, B.J. 2009. Implications of anthropogenic river stage fluctuations on mass transport in a valley fill aquifer. Water Resour. Res., 45(4): 546-550.

Casado, A., Hannah, D.M., Peiry, J.L. and Campo, A.M. 2013. Influence of dam-induced hydrological regulation on summer water temperał ture: Sauce Grande River, Argentina. Ecohydrology, 6(4): 523-535.

Casas, R., Saltveit, S.J. and Alfredsen, K. 2015. The survival of Atlantic salmon (Salmo salar) eggs during dewatering in a river subjected to hydropeaking. River Res. Appl., 31(4): 433-446.

Fritz, B.G. and Arntzen, E.V. 2007. Effect of rapidly changing river stage on uranium flux through the hyporheic zone. Groundwater, 45(6): 753-760.

Gerecht, K.E., Cardenas, M.B., Guswa, A.J., Sawyer, A.H., Nowinski, J.D. and Swanson, T.E. 2011. Dynamics of hyporheic flow and heat 
transport across a bed-to-bank continuum in a large regulated river. Water Resour. Res., 47(3): 104-121.

Greenwood, M.H., Sims, R.C., McLean, J.E. and Doucette, W.J. 2007. Temperature effect on tert-butyl alcohol (TBA) biodegradation kinetics in hyporheic zone soils. Biomed. Eng.Online, 6(1):34-41.

Hamilton, P. 2005. Groundwater and surface water: a single resource. Water Environ. Technol., 17(5): 37-41.

Hancock, P.J. 2002. Human impacts on the stream-groundwater exchange zone. Environ Manag., 29(6): 763-781.

Hanrahan, T.P. 2008. Effects of river discharge on hyporheic exchange flow in salmon spawning areas of a large gravel-bed river. Hydrol. Proc. Int. J., 22(1): 127-141.

Harleman, D.R. 1982. Hydrothermal analysis of lakes and reservoirs. J. Hydraul Eng. Division, 108(3): 301-325.

Hucks, A., Bayani, M., Bomar, A. and Mackey, M. 2009. Impact of dam operations on hyporheic exchange in the riparian zone of a regulated river. Hydrol. Proc. Int. J., 23(15): 2129-2137.

Jones, J., Biology, I. and Fairbanks, U.O. 2000. Streams and groundwaters. J. N. Am. n Benthol. Soc., 19(4): 760-761.

Kiel, B.A. and Cardenas, M.B. 2014. Lateral hyporheic exchange throughout the Mississippi River network. Nat. Geosci., 7(6): 413-417.
Molina, N., Bayer, P., Blum, P. and Cirpka, O.A. 2011. Propagation of seasonal temperature signals into an aquifer upon bank infiltration. Groundwater, 49(4): 491-502.

Nilsson, C. and Berggren, K. 2000. Alterations of riparian ecosystems caused by river regulation: Dam operations have caused global-scale ecological changes in riparian ecosystems. How to protect river environments and the human needs of rivers remains one of the most important questions of our time. BioScience, 50(9): 783-792.

Tonina, D. and Buffington, J.M. 2007. Hyporheic exchange in gravel-bed rivers with pool-riffle morphology: Laboratory experiments and three-dimensional modeling. Water Resour. Res., 43(1): 1421-1435.

Vogt, T., Schirmer, M. and Cirpka, O. 2012. Investigating riparian groundwater flow close to a losing river using diurnal temperature oscillations at high vertical resolution. Hydrol. Earth Sys. Sci., 16(2): 473-487.

Weiwu, C. 2001. Research on the water temperature analysis of reservoir and river downstream. Adv. Sci. Technol. Water Resour., 5(1): 20-23.

Zhou, S., Yuan, X., Peng, S., Yue, J., Wang, X., Liu, H. and Williams, D.D. 2014. Groundwater-surface water interactions in the hyporheic zone under climate change scenarios. Environ. Sci. Pollut. Res., 21(24): 13943-13955. 